\title{
Reliability of Capillary Complete Blood Count in Children With Acute Gastroenteritis
}

\author{
Hanna Wielińska-Wiśniewska, Jan K. Nowak, Michał Dąbrowski, Paula Szydłowska, \\ Mariusz Szczepanik, Katarzyna Cichocka, Patrycja Krzyżanowska-Jankowska and \\ Jarosław Walkowiak*
}

Department of Pediatric Gastroenterology and Metabolic Diseases, Poznan University of Medical Sciences, Poznan, Poland

\section{OPEN ACCESS}

Edited by:

Ana Isabel Lopes,

University of Lisbon, Portugal

Reviewed by:

Lina Jankauskaite,

Lithuanian University of Health Sciences, Lithuania

Aleksandra Zeljkovic

University of Belgrade, Serbia

*Correspondence: Jarosław Walkowiak jarwalk@ump.edu.pl

Specialty section

This article was submitted to Pediatric Gastroenterology,

Hepatology and Nutrition,

a section of the journal

Frontiers in Pediatrics

Received: 27 May 2021

Accepted: 15 July 2021

Published: 10 August 2021

Citation:

Wielińska-Wiśniewska H, Nowak JK, Dąbrowski M, Szydłowska P,

Szczepanik M, Cichocka K,

Krzyżanowska-Jankowska $P$ and Walkowiak J (2021) Reliability of Capillary Complete Blood Count in Children With Acute Gastroenteritis.

Front. Pediatr. 9:715576.

doi: 10.3389/fped.2021.715576
Background: To assess the reliability of complete blood count $(\mathrm{CBC})$ in the capillary blood of children with acute gastroenteritis (AGE), with a focus on leukocytes.

Methods: This was a retrospective cross-sectional study. Complete blood count was compared between the capillary and venous blood in children admitted to a pediatric gastroenterology department with primary diagnosis of AGE (ICD-10 A09, A08.0, A08.2). Capillary blood was obtained in the emergency room and venous blood was sampled in the ward shortly thereafter during peripheral intravenous line placement.

Results: One hundred and forty children were included. The mean ( \pm SD) age and weight of patients were $3.0 \pm 2.9$ years and $16 \pm 9 \mathrm{~kg} ; 26 \%$ had leukocytosis. The mean difference between obtaining results of capillary and venous blood tests was $2 \pm 1 \mathrm{~h}$. Area under the receiver operating characteristic curve (AUC) for the identification of leukocytosis using the capillary blood was 0.98 (95\% Cl 0.96-1.0). The sensitivity and specificity were 86 and 98\%, respectively (accuracy 95\%). The positive and negative predictive values were 94 and 95\%, respectively. The intraclass correlation coefficient revealed high concordance between capillary and venous CBC measurements (leukocyte count 0.94, hemoglobin 0.88, erythrocyte count 0.77 , hematocrit 0.79 , platelet count 0.90 ). Matched pairs comparisons revealed marginally higher erythrocytes (difference of medians: $0.2 \mathrm{~T} / \mathrm{L})$, hemoglobin $(0.3 \mathrm{~g} / \mathrm{dL})$, hematocrit (1.0\%), and platelets $(9 \mathrm{G} / \mathrm{L})$ in the capillary blood.

Conclusion: Capillary CBC is useful in detecting leukocytosis in children with AGE.

Keywords: capillary, complete blood count, full blood count, leukocytosis, accuracy, acute diarrhea in children

\section{INTRODUCTION}

Acute gastroenteritis (AGE) is defined by ESPGHAN as a decrease in the consistency of stools and/or an increase in their frequency, with or without fever or vomiting. AGE remains a leading cause of pediatric hospitalizations, especially in children below 3 years of age (1).

Apart from clinical signs and symptoms of dehydration, physicians in emergency departments often rely on results of blood tests when making decisions on hospital admission. The tests may include electrolyte levels, blood gas ( $\mathrm{pH}$, bicarbonates, base excess) and also a complete blood count $(\mathrm{CBC})$, which helps to rule out more severe conditions. In the ambulatory setting, the 
collection of capillary blood is also less invasive for the patient than venous blood sampling. However, dehydration, small fingers and the poor capillary network may cause technical difficulties in capillary blood sampling among pediatric patients and reduce diagnostic accuracy (2).

These limitations make the value of capillary CBC uncertain, especially in the emergency room in the course of differential diagnosis of vomiting, diarrhea, and/or fever in children. Therefore, the aim of this study was to assess the reliability of capillary CBC in children with AGE.

\section{METHODS}

This cross-sectional study was conducted in Karol Jonscher Clinical Hospital of Poznan University of Medical Sciences, Poznan, Poland. The data were retrospectively collected from electronic health records covering the years 2006-2015. The inclusion criteria comprised: (a) a primary diagnosis of AGE (codes according to ICD-10: A09, A08.0, and A08.2), (b) hematological and electrolyte measurements in the capillary blood in the emergency room and in the venous blood, which were obtained during venipuncture on admission to the hospital, and (c) the time between receiving the results of the two measurements shorter than $4 \mathrm{~h}$. The same methodology was used in our previous study of capillary blood potassium levels (3). The study focused on AGE in order to provide a well-defined group of patients with high availability of the required data.

The capillary and the venous blood samples were analyzed using Sysmex XS-800i and Sysmex XN-1000, respectively (Sysmex Europe GmbH, Norderstedt, Germany). The cut-off for leukocytosis was age-dependent: $20 \mathrm{G} / \mathrm{L}$ (7 days-12 months), 13 G/L (1-6 years), 12 G/L (7-12 years), and 10 G/L (>12 years). The lower limit of the reference range for hemoglobin concentrations was: $13.5 \mathrm{~g} / \mathrm{dL}$ (1st month), $10.0 \mathrm{~g} / \mathrm{dL}$ (2nd month), $9.5 \mathrm{~g} / \mathrm{dL}$ (3-5 months), $10.0 \mathrm{~g} / \mathrm{dL}$ (6-8 months), $10.5 \mathrm{~g} / \mathrm{dL}$ (9th month), $11.0 \mathrm{~g} / \mathrm{dL}$ (10-23 months), $10.9 \mathrm{~g} / \mathrm{dL}$ (2-6 years), $12.0 \mathrm{~g} / \mathrm{dL}$ (7-12 years), $12.0 \mathrm{~g} / \mathrm{dL}$ (>12 years female), $14.0 \mathrm{~g} / \mathrm{dL}$ (>12 years male). Data for leukocyte types or RBC characteristics (e.g., mean corpuscular volume) were not available.

We used Statistica 12 software (Statsoft Inc., Tulsa, USA) to perform the statistical tests, calculate the areas under the curve (AUC) of the receiver operating characteristic, and draw Bland-Altman plots (4). Receiver operating characteristic curve calculations used binary outcome data obtained by comparing venous blood leukocyte count against the above-mentioned age-specific thresholds. The predictor variable was obtained by dividing capillary blood leukocyte concentration by upper limit of the norm for the age. The Youden's index was used to determine the optimal cut-off. The same was done for hemoglobin. The Kolmogorov-Smirnov test was used to test for normality. Forward stepwise regression was used to investigate the influence of age and base excess (as a proxy for dehydration) and other factors on the absolute error of capillary blood measurements.
TABLE 1 | Group characteristics.

\begin{tabular}{|c|c|}
\hline Parameter & \\
\hline Sample size & 140 \\
\hline Age, years & $3.0 \pm 2.9$ \\
\hline $\begin{array}{l}\text { Body weight on admission, } \\
\mathrm{kg}\end{array}$ & $16 \pm 9$ \\
\hline Sex & $54.3 \%$ male $(n=76) 45.7 \%$ female $(n=64)$ \\
\hline $\begin{array}{l}\text { Time from admission to } \\
\text { capillary results, min }\end{array}$ & $11 \pm 42$ \\
\hline $\begin{array}{l}\text { Time from admission to } \\
\text { venous results, min }\end{array}$ & $137 \pm 58$ \\
\hline $\begin{array}{l}\text { Time from capillary to } \\
\text { venous results, min }\end{array}$ & $126 \pm 48$ \\
\hline \multicolumn{2}{|l|}{ Capillary/venous } \\
\hline Hemoglobin, g/dL & $12.8 \pm 1.4 / 12.4 \pm 1.2$ \\
\hline Anemia & $5 \% / 5 \%(n=7)$ \\
\hline RBC count, T/L & $4.7 \pm 0.5 / 4.5 \pm 0.4$ \\
\hline Hematocrit, \% & $37 \pm 4 / 35 \pm 3$ \\
\hline WBC count, G/L & $11.1 \pm 5.9 / 11.2 \pm 5.7$ \\
\hline Leukocytosis & $24 \%(n=33) / 26 \%(n=36)$ \\
\hline Platelet count, G/L & $312 \pm 99 / 322 \pm 111$ \\
\hline Comorbidities & $39 \%$ \\
\hline $\begin{array}{l}\text { Respiratory tract, \% of } \\
\text { cases with comorbidities }\end{array}$ & $60 \%$ \\
\hline \multicolumn{2}{|l|}{ Symptom frequency } \\
\hline Vomiting & $81 \%$ \\
\hline Diarrhea & $64 \%$ \\
\hline Fever & $35 \%$ \\
\hline Lethargy & $26 \%$ \\
\hline $\begin{array}{l}\text { Symptom duration before } \\
\text { admission, days }\end{array}$ & $2.0 \pm 1.3$ \\
\hline Rotaviral infection & $49 \%$ (52 out of 106$)$ \\
\hline $\begin{array}{l}\text { Capillary base excess of } \\
\text { extracellular fluid }\end{array}$ & $-6.9 \pm 4.0$ \\
\hline
\end{tabular}

Means $\pm S D$ are presented

The intraclass correlation coefficient was calculated in an Excel 2016 spreadsheet (Microsoft, Redmond, USA). The design of the project was inspired by STAndards for Reporting Diagnostic accuracy studies (STARD) (5). The study was approved by the Bioethical Committee at Poznan University of Medical Sciences (541/15). It adhered to the tenets of the revised Declaration of Helsinki.

\section{RESULTS}

Out of 1,080 children with the primary diagnosis of acute gastroenteritis, 140 met the inclusion criteria (90 with A09, 40 with A08.0; age range 0-16 years). The group characteristics, including the mean $\pm \mathrm{SD}$ values of basic hematological parameters, are presented in Table $\mathbf{1 .}$

Matched pairs analysis revealed a small yet consistent bias of capillary hemoglobin, RBC count, and hematocrit toward higher values (Table 2). The capillary measurements' absolute 
TABLE 2 | Matched-pairs comparisons of hematologic parameters in capillary and venous blood.

\begin{tabular}{lccccc}
\hline Parameter & Capillary blood & Venous blood & P & Absolute error & Absolute error 5th-95th percentile \\
\hline Hemoglobin, g/dL & $12.5(11.9-13.5)$ & $12.2(11.5-13.1)$ & $<10^{-12}$ & $0.4(0.4-0.6)$ & $0-1.3$ \\
RBC count, T/L & $4.7(4.4-4.9)$ & $4.5(4.2-4.7)$ & $<10^{-19}$ & $0.2(0.1-0.4)$ & $0-0.5$ \\
Hematocrit, \% & $35.9(33.9-38.8)$ & $34.9(33.1-37.5)$ & $<10^{-9}$ & $1.2 \%(0.6-2.4)$ & $0.1-5.2$ \\
WBC count, G/L & $9.8(7.2-13.4)$ & $10.0(7.4-13.5)$ & 0.66 & $0.9(0.4-1.8)$ & $0-4.0$ \\
Platelet count, G/L & $300(247-360)$ & $291(246-379)$ & 0.04 & $18(8-33)$ & $1-112$ \\
\hline
\end{tabular}

Median values (1st-3rd quartiles) are presented. The Wilcoxon test was applied.

TABLE 3 | Correlation coefficients for hematological parameters measured in capillary and venous blood; $p<0.01$ for all correlations.

\begin{tabular}{llll}
\hline Parameter & Pearson's $\mathbf{r}$ & Spearman's $\boldsymbol{\rho}$ & ICC \\
\hline Hemoglobin & 0.92 & 0.89 & 0.88 \\
RBC count & 0.90 & 0.89 & 0.77 \\
Hematocrit & 0.85 & 0.82 & 0.79 \\
WBC count & 0.94 & 0.94 & 0.94 \\
Platelet count & 0.91 & 0.89 & 0.90
\end{tabular}

ICC, intraclass correlation coefficient.

error was low (Table 2). The agreement of measurements in the capillary and the venous blood is illustrated in Bland-Altman plots (Figure 1; Table 3).

AUC for identification of leukocytosis using the measurements in the capillary blood was 0.98 (95\% CI 0.96-1.0). The sensitivity and specificity were 86 and $98 \%$, respectively (accuracy 95\%). The positive and negative predictive values were 94 and $95 \%$, respectively.

AUC for detecting hemoglobin levels corresponding to anemia-not for diagnosing anemia since the patients were dehydrated-was 0.86 (95\% CI $0.68-1.00)$. The sensitivity was $71 \%$ and the specificity $98 \%$, accuracy $97 \%$, positive predictive value $71 \%$, negative predictive value $98 \%$. In seven children, venous hemoglobin levels corresponding to the diagnosis of anemia were found. Five of these were also identified by the capillary blood analysis. However, two false-positive read-outs were also provided by capillary blood analyzers.

Venous hematocrit did not correlate with an absolute error of any of the hematological measurements. Of the five analyzed hematological variables, only RBC count weakly correlated with the difference in time between receiving the results of assessments performed in the venous and the capillary blood (Spearman's $\rho$ $=0.19, p=0.02$ ). However, forward stepwise regression did not confirm any important, independent relationships between the relative or absolute error of capillary $\mathrm{CBC}$ measurements and the aforementioned time difference, age, sex, $\mathrm{pH}$, base excess of extracellular fluid, or urea. A few weak associations $\left(R^{2}<\right.$ 0.20 ) were found using regression: the relative error of capillary hematocrit associated with body weight, hemoglobin correlated with body weight and age, and absolute capillary white blood cell (WBC) count error related to height.

Measurements were grouped time-wise to identify potential systematic bias related to hypothetical changes in sampling or equipment operation practice: $2007-2011(n=40), 2012-2013$ ( $n$ $=59), 2014-2015(n=41)$. The Kruskal-Wallis non-parametric analysis of variance was used to compare the distributions of hematologic parameters between the three groups. Two significant differences were found: WBC concentrations were lower in the years 2007-2011 than from 2012 onwards (venous $p$ $=0.004$ and capillary $p=0.006$, respectively). Because the effect was consistent in the venous and in the capillary blood, we did not ascribe it to a measurement error and assumed that it does not disturb the measures of reliability. Comparison of the two periods (2007-2011 vs. 2012-2015) did not identify differences in age, body weight, the length of stay or other major factors that might be associated with WBC count. However, a shift toward afternoon and evening admissions was noted in the later years ( 1 a.m. \pm 4 h vs. 4 p.m. \pm 5 h previously, $p=0.005$ ). The percentage of admissions after 6 p.m. increased from 13 to $36 \%$.

\section{DISCUSSION}

This is the first study to assess the reliability of capillary $\mathrm{CBC}$ in the setting of AGE. Capillary blood, as well as venous blood measurement, were performed in a specialized medical laboratory, using automated hematology analyzers. This pragmatic study had a sizeable convenience sample, employed a statistical approach suitable for determining diagnostic value, and attempted compensation for potential confounders (2). Overall, the differences between the hemoglobin concentration, hematocrit, WBC, and RBC count in the venous and the capillary blood were practically insignificant.

A recently published study comprehensively reviewed the value of capillary vs. venous blood in the assessment of anemia and called for further research (2). Although the results were inconclusive, most of the identified studies revealed a higher hemoglobin concentration in the capillary blood compared with the venous blood. Our results confirm a marginally higher hemoglobin in capillary vs. venous samples. Capillary $\mathrm{CBC}$ has a lower sensitivity in the diagnosis of anemia and should not be used to this aim, at least unless its limitations are thoughtfully considered (6-9).

Multiple biological factors influencing the accurateness of capillary blood hemoglobin concentration measurement in AGE were found. This study revealed that body weight and age slightly affected accuracy of capillary hemoglobin and hematocrit measurements. Previous research pointed toward the dependence of the value of capillary CBC on sex, which could be 



FIGURE 1 | Bland-Altman plots illustrate the agreement between capillary and venous measurements of hemoglobin (A), red blood cells (B), hematocrit (C), leukocytes (D) and platelets (E). $1 \mathrm{G} / \mathrm{L}=1000 / \mu \mathrm{L} ; 1 \mathrm{~T} / \mathrm{L}=1000$ 000/L.

mediated by the vasoconstrictive effect of androgens. As in males capillaries contain less RBCs, hence less hemoglobin (10). This study found no effects of sex on obtained differences between capillary and venous CBC in AGE.

The method of capillary blood sample collection also significantly affects results. Hemoglobin concentration in pooled sample drops is higher than in the single drop of capillary blood (6). Therefore, the pooled sample method (also used herein) more precisely reflects the actual hemoglobin. This study indicates that capillary $\mathrm{CBC}$ may be more precise in the estimation of hemoglobin concentration among younger children and those with lower body weight, despite increased technical difficulties in sampling capillary blood. Similar results were obtained previously (11).

Platelets (PLT) and WBC count belong to essential CBC measurements. PLT levels are known to be significantly underestimated in the capillary samples (12-16). On the contrary, WBC count is higher in the capillary than in reference 
venous blood $(12,14,17-20)$. This analysis did not reveal analogous differences.

The main aim of this retrospective work was to determine the reliability of capillary CBC in AGE, which results in dehydration. No relationships were found between base excess corrected for the extracellular fluid (BE-ECF) and the accuracy of capillary CBC. BE-ECF can only estimate the level of dehydration, which is challenging to assess correctly even using complex clinical questionnaires.

In summary, despite being prone to biological, technical and environmental confounders, capillary $\mathrm{CBC}$ is useful in detecting leukocytosis in children with AGE (21).

\section{DATA AVAILABILITY STATEMENT}

The raw data supporting the conclusions of this article will be made available by the authors, without undue reservation.

\section{REFERENCES}

1. Guarino A, Ashkenazi S, Gendrel D, Lo Vecchio A, Shamir R, Szajewska H, et al. European Society for Pediatric Gastroenterology, Hepatology, and Nutrition/European Society for Pediatric Infectious Diseases evidence-based guidelines for the management of acute gastroenteritis in children in Europe: update 2014. J Pediatr Gastroenterol Nutr. (2014) 59:132-52. doi: 10.1097/MPG.00000000000 00375

2. Karakochuk CD, Hess SY, Moorthy D, Namaste S, Parker ME, Rappaport AI, et al. Measurement and interpretation of hemoglobin concentration in clinical and field settings: a narrative review. Ann N $\quad Y \quad$ Acad Sci. (2019) 1450:126-46. doi: 10.1111/nyas. 14003

3. Nowak JK, Wielińska H, Dabrowski M, Szydłowska P, Szczepanik M, Krzyzanowska P, et al. Reliability of capillary blood potassium measurements in children with acute gastroenteritis. Arch Dis Child. (2018) 103:1091-3. doi: 10.1136/archdischild-2017314561

4. Krouwer JS. Why Bland-Altman plots should useX, not $(\mathrm{Y}+\mathrm{X}) / 2$ whenX is a reference method. Stat Med. (2008) 27:778-80. doi: 10.1002/ sim. 3086

5. Bossuyt PM, Reitsma JB, Bruns DE, Gatsonis CA, Glasziou PP, Irwig L, et al. STARD 2015: an updated list of essential items for reporting diagnostic accuracy studies. BMJ. (2015) 351:h5527. doi: 10.1136/bmj. h5527

6. Neufeld LM, Larson LM, Kurpad A, Mburu S, Martorell R, Brown KH. Hemoglobin concentration and anemia diagnosis in venous and capillary blood: biological basis and policy implications. Ann N Y Acad Sci. (2019) 1450:172-189. doi: 10.1111/nyas. 14139

7. Hinnouho G-M, Barffour MA, Wessells KR, Brown KH, Kounnavong S, Chanhthavong B, et al. Comparison of haemoglobin assessments by HemoCue and two automated haematology analysers in young Laotian children. J Clin Pathol. (2018) 71:532-8. doi: 10.1136/jclinpath-2017204786

8. Morris SS, Ruel MT, Cohen RJ, Dewey KG, de la Brière B, Hassan MN. Precision, accuracy, and reliability of hemoglobin assessment with use of capillary blood. Am J Clin Nutr. (1999) 69:1243-1248. doi: 10.1093/ajcn/69. 6.1243

9. Karakochuk CD, Janmohamed A, Whitfield KC, Barr SI, Vercauteren SM, Kroeun $\mathrm{H}$, et al. Evaluation of two methods to measure hemoglobin concentration among women with genetic hemoglobin disorders in Cambodia: a method-comparison study.

\section{ETHICS STATEMENT}

The study was approved by the Bioethical Committee at Poznan University of Medical Sciences (541/15). Written informed consent from the participants' legal guardian/next of kin was not required to participate in this study in accordance with the national legislation and the institutional requirements.

\section{AUTHOR CONTRIBUTIONS}

HW-W, JN, MD, PS, PK-J, and JW: conceptualization. HW-W, JN, MD, and PS: data curation and formal analysis. HW-W, JN, MS, KC, PK-J, and JW: investigation. JN: project administration. HW-W and JN: writing-original draft. MD, PS, MS, KC, PK-J, and JW: writing-review and editing. JW: funding acquisition and supervision. All authors have approved the final article.
Clin Chim Acta. (2015) 441:148-55. doi: 10.1016/j.cca.2014. 12.021
Murphy WG. The sex difference in haemoglobin levels in adults - mechanisms, causes, and consequences. Blood Rev. (2014) 28:41-7. doi: 10.1016/j.blre.2013. 12.003

11. Neufeld L, García-Guerra A, Sánchez-Francia D, Newton-Sánchez O, Ramírez-Villalobos MD, Rivera-Dommarco J. Hemoglobin measured by Hemocue and a reference method in venous and capillary blood: a validation study. Salud Publica Mex. (2002) 44:219-27. doi: 10.1590/S0036-36342002000 300005

12. Daae LN, Halvorsen S, Mathisen PM, Mironska K. A comparison between haematological parameters in "capillary" and venous blood from healthy adults. Scand J Clin Lab Invest. (1988) 48:723-6. doi: 10.3109/003655188090 85796

13. Chavan P, Bhat V, Tiwari M, Gavhane U, Pal SK. Comparison of complete blood count parameters between venous and capillary blood in oncology patients. J Lab Phys. (2016) 8:065-6. doi: 10.4103/0974-2727.176238

14. Kayiran SM, Ozbek N, Turan M, Gürakan B. Significant differences between capillary and venous complete blood counts in the neonatal period. Clin Lab Haematol. (2003) 25:9-16. doi: 10.1046/j.1365-2257.2003. 00484.x

15. Feusner JH, Behrens JA, Detter JC, Cullen TC. Platelet counts in capillary blood. Am J Clin Pathol. (1979) 72:410-4. doi: 10.1093/ajcp/ 72.3.410

16. Tai DY, Chan KW, Chee YC, Mak KH. Comparison of platelet counts in simultaneous venous and capillary blood samples using an automated platelet analyser. Singapore Med J. (1995) 36:263-6.

17. Papa F, Rongioletti M, Majolini MB, Collegiani V, Vaccarella C, Notarmuzi ML, et al. Fast bedside measurement of blood count and C-reactive protein in newborns compared with conventional methods. Clin Lab. (2012) 58:951-7. doi: 10.7754/Clin.Lab.2011.110628

18. Schalk E, Heim MU, Koenigsmann M, Jentsch-Ullrich K. Use of capillary blood count parameters in adults. Vox Sang. (2007) 93:348-53. doi: 10.1111/j.1423-0410.2007.00978.x

19. Daae LN, Hallerud M, Halvorsen S. A comparison between haematological parameters in "capillary" and venous blood samples from hospitalized children aged 3 months to 14 years. Scand J Clin Lab Invest. (1991) 51:6514. doi: 10.3109/00365519109104576

20. Yang ZW, Yang SH, Chen L, Qu J, Zhu J, Tang Z. Comparison of blood counts in venous, fingertip and arterial blood and their measurement variation. Clin Lab Haematol. (2001) 23:155. doi: 10.1046/j.1365-2257.2001.00388.x

21. Tamelyte E, Vaičekauskiene G, Dagys A, Lapinskas T, Jankauskaite L. Early blood biomarkers to improve sepsis/bacteremia diagnostics 
in pediatric emergency settings. Med Kaunas Lith. (2019) 55:99. doi: 10.3390/medicina55040099

Conflict of Interest: JN reports personal fees from Norsa Pharma, a grant from Biocodex Microbiota Foundation, and non-financial support from Nutricia outside the submitted work. JW reports personal fees and non-financial support from Biocodex, BGP Products, Chiesi, Hipp, Humana, Mead Johnson Nutrition, Merck Sharp \& Dohme, Nestle, Norsa Pharma, Nutricia, Roche, Sequoia Pharmaceuticals, and Vitis Pharma, outside the submitted work, and also grants, personal fees and non-financial support from Nutricia Research Foundation Poland, also outside the submitted work.

The remaining authors declare that the research was conducted in the absence of any commercial or financial relationships that could be construed as a potential conflict of interest.
Publisher's Note: All claims expressed in this article are solely those of the authors and do not necessarily represent those of their affiliated organizations, or those of the publisher, the editors and the reviewers. Any product that may be evaluated in this article, or claim that may be made by its manufacturer, is not guaranteed or endorsed by the publisher.

Copyright (c) 2021 Wielińska-Wiśniewska, Nowak, Dạbrowski, Szydłowska, Szczepanik, Cichocka, Krzyżanowska-Jankowska and Walkowiak. This is an openaccess article distributed under the terms of the Creative Commons Attribution License (CC BY). The use, distribution or reproduction in other forums is permitted, provided the original author $(s)$ and the copyright owner(s) are credited and that the original publication in this journal is cited, in accordance with accepted academic practice. No use, distribution or reproduction is permitted which does not comply with these terms. 